\title{
The implementation and evaluation of a new learning space: a pilot study
}

\author{
Gail Wilson $^{\mathrm{a} *}$ and Marcus Randall ${ }^{\mathrm{b}}$ \\ ${ }^{a}$ Teaching and Learning Centre, Southern Cross University, Gold Coast, Australia; ${ }^{b}$ Faculty of \\ Business, Bond University, Gold Coast, Australia
}

(Received 22 April 2011; final version received 14 October 2011)

\begin{abstract}
A dramatic, pedagogical shift has occurred in recent years in educational environments in higher education, supported largely by the use of ubiquitous technologies. Increasingly, emphasis is being placed on the design of new learning spaces, often referred to as "Next Generation Learning Spaces" (NGLS) and their impact on pedagogy. The traditional idea of "classroom" now incorporates the use of both physical and virtual space. Increasing availability of digital technologies has enabled access by teachers and students to a wider range of communication and information that can now be incorporated into the formal learning process. This change has meant a greater focus on the design and use of flexible learning spaces, more use of blended learning approaches and more personalised, individualised learning opportunities for students. While many such classrooms have been built and used in universities globally, only a few formal studies have been reported on how these spaces are used by both teachers and students. This article focuses on a pilot study of the use by academic staff and students of a next generation learning space - the Pod Room - and makes recommendations for further research into the effectiveness of new learning spaces in universities.
\end{abstract}

Keywords: next generation learning spaces; blended learning; case study

\section{Introduction}

Bond University is a private, single campus university located on the Gold Coast in Australia, which celebrated its 20th anniversary in 2009. The university operates across three academic semesters a year allowing students to complete their undergraduate degrees in two years. The student cohort at Bond comprises Australian students and overseas students from 47 different countries. The University's focus is on face-to-face small group teaching and individualised attention given to students. In 2007 the University revamped one of its traditional classrooms into a next generation learning space called the Pod Room, taking its name from the kidneyshaped, group work desks that are a feature of the room. This space was designed to facilitate collaborative group work activities across a range of disciplines. The reconstruction of this space was part of a move in other universities across Australia to create new learning spaces spurred by the emphasis of the Australian Learning and Teaching Council (ALTC)'s funding of the Next Generation Learning Spaces (NGLS) Project (Radcliffe et al. 2009). Both authors were contributors to this project.

*Corresponding author. Email: gail.wilson@scu.edu.au 
In this paper, learning spaces are defined as "those spaces which encompass the full range of places in which learning occurs, from real to virtual, from classroom to chat room" (Brown 2005). The paper begins with a literature review summarising the emerging literature in this area, followed by a description of the pilot study and the methodology used to gather data. Both qualitative and quantitative analyses of the data obtained in the study are then presented, followed by conclusions and future research directions of this work.

\section{Literature review}

The literature relating to learning spaces is diverse and ranges on a continuum from general to more detailed in conceptualisation and analysis with various perspectives explored - architecture, space design, pedagogy, staff and student needs, and stakeholder involvement in the design process. Across this literature there is a consistent view that universities should be more innovative and creative in the ways that they use, reconfigure and/or build new learning spaces to meet the expectations of tomorrow's students. There is broad agreement that learning spaces should be student-centred rather than teacher-centred; have the necessary technology and furnishings to meet student and "subject" needs; support pedagogic, multidisciplinary, multimedia formats that engage the student; and be flexible, ergonomically comfortable, functional and multi-usable. Importantly, embedding technology into teaching and learning spaces is "more of an evolutionary process than a revolutionary one" (Joint Information Systems Committee 2006, 6). Learning spaces are part of the "new learning paradigm" and institutions wanting to be leaders in this area need to implement "new paths for teaching, learning and space utilisation" (Johnson and Lomas 2005, 14). The emerging area of learning space design is the link that integrates the pedagogy of learning spaces with the technology that is used within them.

This section of the paper draws on a sample from a larger number of publications used to frame this study from the US and the UK as well as some Australian literature arising from the NGLS project mentioned above, and a more recent ALTC project (Lee and Tan 2011) which supports the direction of the findings of this paper. This literature was subsequently categorised by the authors as (1) principles or guidelines for practice, (2) descriptions of practice and (3) research-oriented, with some of the literature providing a blend of (1) and (2).

\section{Principles or guidelines for practice}

One strand of the literature focused on principles or guidelines for practice addresses the issues surrounding learning space design principles for new as well as repurposed learning spaces within an institution, or anticipating what the future of learning spaces may hold (Brown 2009; Brown and Lippincott 2003; Francis and Raftery 2005; Jamieson, Dane, and Lippman 2005; Johnson and Lomas 2005; Long and Ehrmann 2005; Oblinger 2005).

While in some of this literature the style of writing can be idealised and uncritical there is value in the guidance provided on a range of issues connected with learning spaces. These issues include the relationship between new spaces for learning and student learning theory; key approaches to the design of learning spaces; the need for linkage between learning spaces and institutional approaches to teaching and 
learning; and attention to the need for integration of spaces for learning - formal and informal, internal and external - across the institution.

The convergence of pedagogy, space and technology provides a framework with which to address a host of issues associated with the design of learning spaces (Oblinger 2005): the need for an institutional vision to guide planning, which can be expressed as a set of "learning principles" to guide the design process; the types of analysis and information gathering an institution should do prior to the design of the space; major design principles to guide the design of such spaces; and the importance of ongoing assessment of new learning spaces to inform improvements to current spaces and frame the design of future ones (Brown and Lippincott 2003).

New learning spaces are described in different ways across the literature. In the case of one UK university its institutional framework for blended learning has helped define a "blended learning landscape" for the campus which focuses on the physical spaces of a blended learning environment that promote student collaboration, flexibility of access and use of reusable learning resources in a technology-enhanced learning environment (Francis and Raftery 2005). The concept of "learning precincts" (Jamieson, Dane, and Lippman 2005, 21), formal/informal and internal/ external areas of a campus, captures the imagination in the visualisation of the entire campus space within which links are formed between spaces that would normally be independent of each other. Learning spaces are also seen of as a series of overlapping, cross institutional networks, a single "ecology" (Brown 2009, 66) to guide the planning, construction and maintenance of spaces, facilitate standardisation of technology across the campus, link formal, informal and virtual spaces, and facilitate flexibility of use for the campus community. In this perspective all members of the community have a role to play in ensuring the success of these spaces.

Some of the learning spaces literature is futuristic in style, where, in answer to the question "What will the classroom of the future look like?" authors attempt to forecast what they see as the future for learners, learning and learning spaces. Two researchers (Long and Ehrmann 2005, 56) speculate that the well-designed classroom of the future will need to be comfortable and inviting, accommodating of specific types of learning activities and of different technologies brought to the space. They also need to afford flexible and variegated use across a range of disciplines and offer 24/7 access.

\section{Descriptions of practice}

The literature on practice focuses on descriptions of innovation in relation to new learning spaces, particularly emphasising the planning of these spaces before the architects commence their work. The Joint Information Systems Committee (JISC) (2006) in the United Kingdom offers a comprehensive and visual guide to those planning and designing $21^{\text {st }}$ century learning spaces, combining text, visual representations and photographs of specific spaces in higher and further education institutions in the United Kingdom. These spaces include entrances to buildings, teaching precincts, learning centres and social spaces. In a number of case studies from universities in Singapore, Australia and the United States, new learning spaces have been deliberately planned to promote an inquiry approach to learning, quite different from traditional teaching and learning spaces in universities (Long and Holeton 2009). Both physical and virtual learning spaces are considered as part of the planning process. Planning for evaluation of new learning spaces that links learning space performance to student learning outcomes also needs to occur (Dugdale 2009). 


\section{G. Wilson and M. Randall}

\section{Research-oriented literature}

The research literature on new learning spaces is a developing field. Some research findings have emerged from learning space projects that have been formally evaluated in the United States (Hunley and Schaller 2009; Tom, Voss, and Scheetz 2008), and a broad review of the learning spaces research literature (Temple 2008) has noted areas for further research. In this section the discussion on evaluation of learning spaces is limited to two studies supported by the ALTC - the case studies of evaluation of learning spaces within the NGLS project report mentioned earlier in this paper (Radcliffe et al. 2009), and a more recent project (Lee and Tan 2011) which has published results from the trials of a learning space evaluation model.

A key output of the NGLS project is the Pedagogy-Space-Technology (PST) Design and Evaluation Framework (Radcliffe 2009, 11-16) by which new learning spaces can be both designed and evaluated. This framework is designed for a range of users across a wide span of projects and institutions. Within the framework, the three areas of pedagogy space and technology influence each other and key questions for evaluating learning spaces are framed within each of these three areas. The PST framework is useful for all institutions wishing to evaluate the impact of their spaces in these three areas. In this study it has been is used to frame the discussion of findings found later in this paper. Figure 1 represents the framework diagrammatically.

User surveys are the most popular way of evaluating teaching spaces across the cases that were part of the NGLS project, followed by observational studies. No empirical measures of gathering evaluation data were found in any of the cases, although the project report acknowledged that new learning spaces are more "space hungry" than traditional lecture and tutorial rooms and given this fact, it will be increasingly important "to gather evidence of positive outcomes from these spaces to counter the inevitable... questions of space efficiency" (Radcliffe et al. 2009, 30). Findings from the individual case studies highlighted the benefits of a planned, collaborative approach to the design of learning spaces (Huon and Sharpe 2009); the need for timely, pedagogical advice for teaching staff in the use of these spaces to gain optimal use of their features (Andrews and Powell 2009); and the requirements for responsive technical support for the space (Reushle et al. 2009).

A more recent ALTC project (Lee and Tan 2011) has focused on a learning evaluation model trialled across three Australian universities. Each institution's trial evaluation focused on different types of learning spaces: a 24/7 learning space, a Learning Commons, and an Advanced Concept Teaching Space (ACTS).

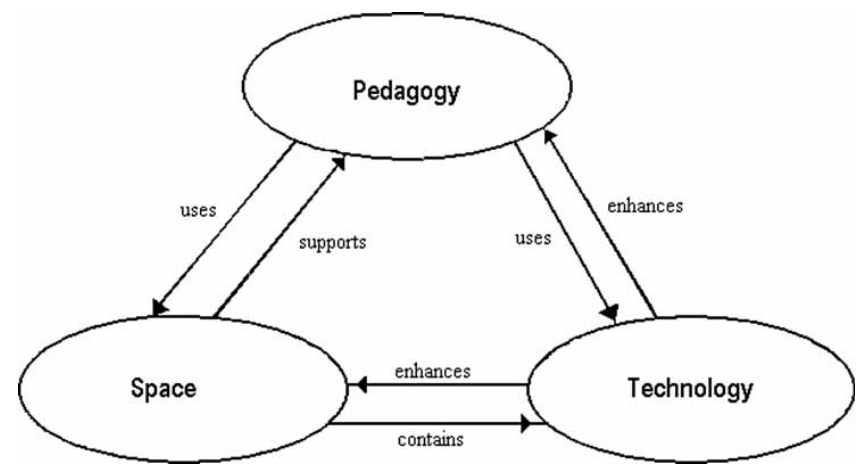

Figure 1. The PST framework (adapted from Radcliffe 2009, 13). 
Of immediate interest to the Pod Room study are some of the findings from the evaluation of the ACTS space - the need for teachers to "re-imagine" their teaching; the learning design of subjects and courses taught in these new spaces; and a need for integrated but broad-based approach to learn in these new spaces; and an "integrated but broad-based approach to imagining future learning landscapes" (Lee and Tan 2011, 15).

\section{Pod Room pilot study}

This study of the Pod Room was conducted in 2008 across two teaching semesters. The following section presents details about the characteristics of the room and the rationale for conducting the pilot study.

\section{Characteristics of the Pod Room}

The Pod Room comprises a number of integrated components as described in Table 1 - five student pods, a single Master pod, an informal breakout area and whiteboards. Figure 2 shows the layout of the Pod Room.

\section{Rationale for the pilot study}

The rationale for our study was to inform innovation at the university and contribute to the research literature on learning spaces through its formal evaluation of a grouporiented new learning space. The focus of the pilot study was to investigate and analyse the user-centred design and flexibility of the Pod Room space in relation to the three areas of technology, space and pedagogy. Through dissemination such as this paper, we also intended our findings and the investigative framework in Figure 1 to inform the design and use of such spaces, not only at our home institution, but further afield as well.

It was also necessary to develop a greater understanding of what constituted "blended learning" for the Bond campus overall. Littlejohn and Pegler $(2007,26)$ see blended learning as "a hybrid model of e-learning that allows coexistence of conventional face-to-face teaching methods and newer e-learning activities and resources together in a course." At the time of this study, blended learning was in its early stages of adoption across the university. The Blackboard ${ }^{\mathrm{TM}}$ learning management system (LMS) had been introduced in 2006. Emphasis was placed on maintaining high quality, face-to-face staff-student contact, while also encouraging technology-enhanced blended learning environments that fostered further innovation in the use of technologies in teaching and learning across disciplines. A 2009 survey of teachers' use of this system conducted by the university's Teaching and Learning Centre recommended the need for the university to articulate clearly a vision for blended learning across the campus.

\section{Methodology}

A total of seven academic staff comprised the sample for this pilot, four women and three men, selected from a list of academics who had expressed interest in participating in the pilot, and who also represented a spread of disciplines across 
Table 1. Pod Room integrated components.

Components

Student pods

Master pod

Informal breakout area

Whiteboards
Description

These are designed to seat a maximum of six students to form a class working group. Each pod has a networked computer that is connected to dual screens. Given the width of the pod two screens are necessary but they display only a single image. The facility is also available to allow students to connect their own notebook computer to the pod. Additionally, a lighting control is mounted in each desk which allows the students to change the level of lighting directly over their pod.

The teacher's workspace used to control the entire room. It has the ability to override any of the students' settings such as lighting control. All controls are inbuilt into a single touch panel. Technological features of the Master pod include:

- All lighting - There are front and back house lights, as well as down lights for each pod. Each light can be controlled individually from the Master pod.

- Dual projectors - These are wide screen projectors that are capable of displaying computer output as well as DVD movies.

- Image switching - Images from each pod (including the Master pod) can be switched to any other pod or projector. This flexibility gives the room many of its educational advantages. The teacher may also choose to preview the image on their screen first before putting it to another device, such as a projector.

- Document camera - This allows the facilitator to demonstrate real world objects. For example, a marketing academic may wish to display a commercial product.

- DVD Player - A range of instructional movies and real-world case studies can be displayed this way.

- Touch pen - The pen acts as a mouse and an annotation tool. Often this is used to mark-up a document for illustrative purposes.

- External AV and computer input - The teacher can use their own notebook computer and/or video equipment (such as an MP3 player) instead of the one inbuilt.

This area contains several ottoman furniture pieces. The furniture can be pushed into any configuration and serves to allow groups to talk with one another away from the pod area. Teachers can use this area to bring students together at the end of a class for a final discussion and overview of the learning that has taken place in that particular class.

Four whiteboards are located on the side walls to allow student groups to explore ideas for problem solving. As the facilitator has electronic annotation facilities available, there is no whiteboard at the front of the room.

the university. Five of the seven teachers in the pilot taught undergraduate (UG) students and two of the staff in teacher education taught postgraduate (PG) students only. Table 2 shows a list of these staff and their discipline.

Ethical clearance was gained from the university to conduct this research. An initial meeting was arranged with each teacher to explain the nature of the pilot and to obtain their agreement to participate. A pseudonym was used for each teacher in the study. All teacher and student participants were asked to read an Information Statement about the study and sign a consent form indicating their willingness to participate in the study. 


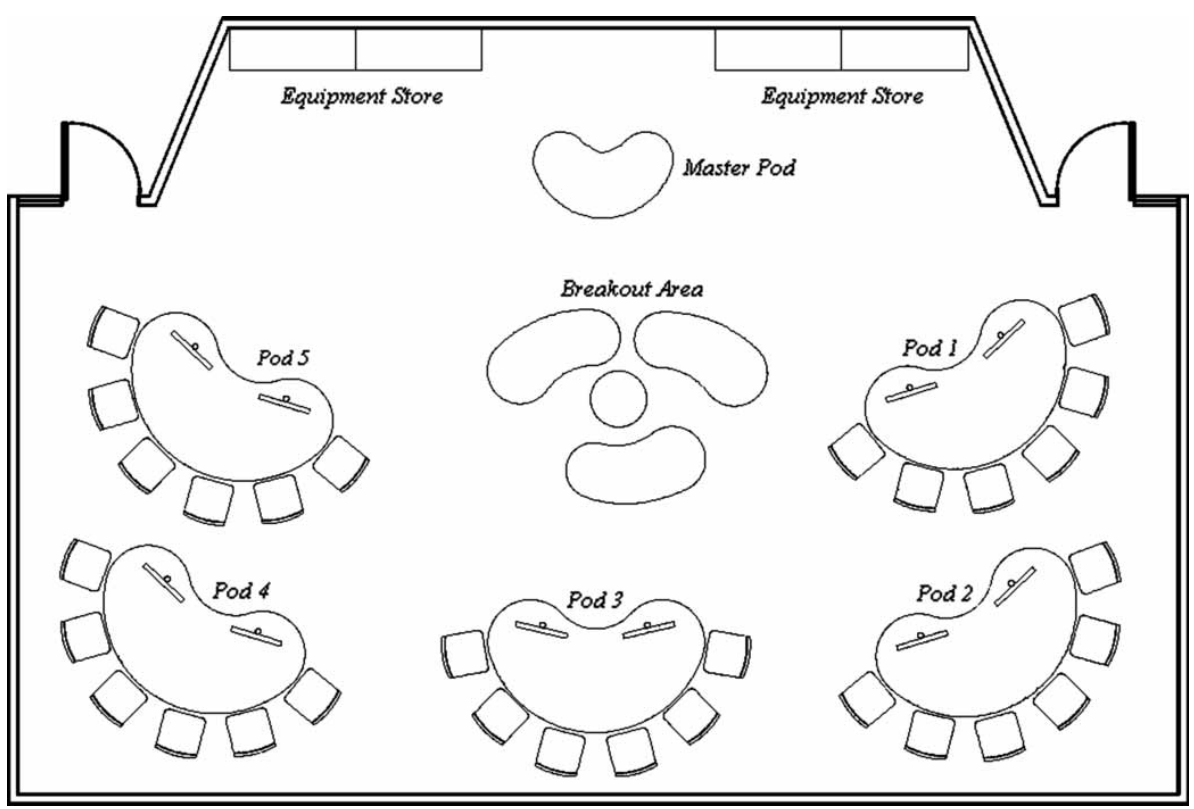

Figure 2. Pod Room layout.

The principal author observed one class in the Pod Room for each of the teachers and took notes on what was observed in each class. A 30-minute interview about the teaching observation scheduled as close as possible to the observed class was then organised with each teacher. All interviews were transcribed and a copy returned to each teacher for checking. Each interview focused on one to two issues that had emerged from the observation of the classes beforehand - a particular pedagogical approach used by the teacher, the mix of technologies used in the class, etc. Finally, an emailed survey was administered to each academic at the end of the semester. Teachers in the study were also asked on a weekly basis to record their ideas, thoughts and concerns as they used the Pod Room on a personal blog space created in a Blackboard ${ }^{\mathrm{TM}}$ community site created to support the study. The authors of this paper had access to this blog space for the duration of the study. All seven staff made more than one posting to the blog, with three staff making multiple postings over the duration of the study. Information gained from analysis of the blog space comments, the interviews and observation data were used to support and amplify findings from the staff survey.

Table 2. Teachers and disciplines involved in the pilot study.

\begin{tabular}{ll}
\hline Teacher & Discipline \\
\hline 1 & Languages \\
2 & Sustainable development \\
3 & Teacher education (PG) \\
4 & Teacher education (PG) \\
5 & Marketing \\
6 & Health sciences \\
7 & Information Technology \\
\hline
\end{tabular}


The staff survey questions are provided below:

(1) How has the use of the Pod Room impacted on the way you teach this subject?

(2) What types of learning activities do you find this space has facilitated well?

(3) What have been the differences, if any, between the way you used this space and other spaces where you have taught this subject?

(4) How has the use of this space impacted on your role as a teacher?

(5) What do you perceive as the impact this space has had on the student's experience of learning?

(6) What would you add/change/remove from the current Pod Room and why?

A total of 56 students participated in the pilot by completing a survey in class time about their experiences of the Pod Room at the end of the semester. Surveys were distributed by individual teachers and collected and returned by internal mail to the principal author. Six questions were included in the student survey, with the sixth question the same as that asked of the teachers:

(1) How has the design of the Pod Room space impacted on the way you approach your learning in this subject?

(2) What differences, if any, did you notice this past semester about the way you used this space in your subject, in comparison to the way you engage in small group activities in other group teaching spaces?

(3) Have you noticed any change in the way you interacted with your teacher?

(4) Have you noticed any change in the way you interacted with other students?

(5) Has any aspect of the way you worked as a student in this room really stood out above all others? If so, please describe.

(6) What would you add/change/remove from the current Pod Room and why?

\section{Analysis of data}

\section{Staff survey data}

Teacher responses to the survey questions are summarised in Table 3 below. All teachers responded to all six survey questions. For the last question, the responses belong neither to the "positive summary" nor the "negative summary" categories. The survey responses, together with the interview data and comments from the blog spaces were further analysed using the PST framework mentioned earlier in this paper. These results are presented in the Findings section of this paper.

\section{Student survey data}

Table 4 provides a summary of the results from the student surveys. Column 2 in the table shows the overall response rate to the question and the number of responses coded as positive, negative or no difference to each question. Note that for the last question responses belong neither to the "positive summary" nor the "negative summary" categories. The survey responses were further analysed using the PST framework mentioned earlier in this paper. 
Table 3. Analysis of staff survey questions.

Questions $\quad$ Positive summary Negative summary

How has the use of the Pod Room impact on Students able to work collectively and effectively on PBL

the way you teach this subject?

(problem-based leaning) scenarios; students can access the

Internet and share work with the class; allows activities that encourage student autonomy; flexible learning space

promoted awareness of student learning; allows extended

learning activities to be introduced; allows student centred teaching

What types of learning activities do you find Sharing work of individual groups to the whole class; enabled this space has facilitated well? collaborative learning; enabled PBL activities; easy transition from desk-based activities to class discussion; allows relaxed group discussion; the breakout area facilitates discussion

What have been the differences, if any, between the way you used this space and other spaces where you have taught this subject? greater sharing potential; Internet access encourages

Students locked into groups, though rearrangement was possible

flexible seating allows for more academic and social environments

How has the use of this space impacted on your Group work activities, enabled by the pods, engaged role as a teacher?

students; the room encourages independent learning and peer support

What do you perceive as the impact this space has had on the student's experience of learning?

Students liked appearance of the room and technology available; the breakout area encouraged student discussion and participation; more effective use of class time; student liked the elevated level of interaction that the room encouraged; greater ownership of their learning; positive group work experiences

What would you add, change or remove from the Pod Room and why?

We need a remote control for slides; independent sound systems required for each pod; need simpler controls for the console; technology in the room should be checked regularly; having the lectern can be inconvenient; whiteboards on the sides of the room can be hard to utilise; having a movable, group work table

Frustration when equipment not working; visual interference to the front of the room; positioning of whiteboards at the side of the room; lack of instructions in the room as to how to operate the touch panel in the Master pod. 
Table 4. Analysis of student survey data.

\begin{tabular}{ll}
\hline Question Discussion &
\end{tabular}

Positive summary

Negative summary

1. How has the design of the Pod Room 96\% response rate. The majority of space impacted on the way you approached your learning in this subject? responses were positive towards the impact the Pod Room had on their learning. Thirteen students responded negatively to this question. Five students recorded no impact.

2. What differences you noticed abou the way you used this space this past semester in this subject from the way you engage in small group activities in other small group teaching spaces?

3 . Have you noticed any change in the $62 \%$ response rate. The majority of way you interacted with your teacher in responses were positive. Seven this space?

students responded negatively to the question. Fourteen respondents indicated no change.

4. Have you noticed any change in the $60 \%$ response rate. The majority way you interacted with other students? of responses were positive. Eleven students responded negatively to the question. Ten respondents reported no difference.
Clear access to content and resources; more Unhelpful technology; physical obstrucinteractivity; flexible layouts; design facili- tions in the room; this subject did not suit tated expression of ideas this space

Computers can lead to an impersonal class; computer monitors are in the way; desks are too distant from each other

More visible presentations; increased relaxed Computer screens affected the communicommunications; easy to see cation negatively; design of the Master pod made it difficult to have eye contact with the teacher; desks too far away and spread out to have eye contact with the teacher

More frequent and effective communication; Less activity with students and more with facilitated sharing written work across computers; sitting two at a table makes partners more accessible; interaction and sharing of ideas with everyone at the same computers; only interacted with those at my desk; no extended friendships because other students too far away time; sharing with others made learning more interesting 
Table 4 (Continued)

\begin{tabular}{|c|c|c|c|}
\hline Question & Discussion & Positive summary & Negative summary \\
\hline $\begin{array}{l}\text { 5. Has any aspect of the way you } \\
\text { worked as a student in this room really } \\
\text { stood out above all others? } \\
\text { If so, please describe }\end{array}$ & $52 \%$ response rate. & $\begin{array}{l}\text { Screens on both sides of room facilitated } \\
\text { group work, could see the work of others; } \\
\text { able to communicate better and with more } \\
\text { confidence as there was individual access to } \\
\text { information to support my ideas; commu- } \\
\text { nication } \\
\text { easier with teacher and class; more comfor- } \\
\text { table space; more engaged; more effective } \\
\text { group work and more enjoyable; easier to } \\
\text { facilitate class activities and discussions; } \\
\text { aided learning }\end{array}$ & Feeling of isolation \\
\hline $\begin{array}{l}\text { 6. What would you add, change or } \\
\text { remove from the Pod Room and why? }\end{array}$ & $51 \%$ response rate. & $\begin{array}{l}\text { Poor quality sound systems; all computers } \\
\text { need to be working properly and consis- } \\
\text { tently; pods that fit three people and } \\
\text { computers; provide instructions in the room } \\
\text { as to how to use it; fewer chairs and more } \\
\text { space to move around; screen on desk is a } \\
\text { distraction and blocks eye contact with } \\
\text { lecturer; lights on Master pod distracting; } \\
\text { separated the class too much }\end{array}$ & \\
\hline
\end{tabular}

separated the class too much 


\section{Findings}

Findings from the analysis of both staff and student data gathered during the project are presented below using the Pedagogy - Space - Technology framework.

\section{Pedagogy (teaching and learning)}

A large number of participants, both staff and students, reported positive improvements in interactivity and engagement as a result of their experiences in the Pod Room, arising from the increased opportunities the space afforded for communicative, collaborative, role-playing and problem-based learning style tasks. A few of the staff commented on the ability to facilitate exploratory/discovery style tasks that led to greater individual and group autonomy. The tasks and topics could be "bigger" without "pedantic little exercises". More than half of the staff commented on a reduction in "teaching", in favour of facilitating and guiding more learning-centred teaching. A few staff commented on an increase in selfreflection about their teaching and that teaching in the space over the period of the pilot study had widened their options in terms of choice of teaching strategies A couple of staff made comments about the need to redesign their subjects to better suit the capabilities of the room, and that they needed time for experimentation within the space to maximise the space's full potential. A single staff member commented on the "off-the-cuff" capabilities of the room, while another highlighted the flexible curriculum that can develop from having a flexible learning space like the Pod Room.

From observations of the teachers' classes during data collection, most used a blend of learning activities that combined the use of technologies, individual work and face-to-face discussion. One example of this occurred in a language class in which the teacher made use of websites for key word searches, online games for new vocabulary acquisition and other learning activities that moved smaller groups into larger ones. She also shifted students from their pod desks to the informal learning space at the front of the room for an end-of-class conversation.

Positive student responses focused overwhelmingly on increased interaction with their classmates in the form of discussion, sharing of ideas, greater participation and the opportunities for peer learning. More than a few students commented on the improved relationship and increased approachability of their teachers, which some attributed to extended communication afforded by the space. One student commented that "the Pod Room is perfect for group work and presentations". Another highlighted the space allowed "open discussion on an even platform as opposed to not really engaging by commenting and reflecting on what others say". Another stated "I asked more questions and got concepts clarified if I didn't understand" and "I was able to hear and understand the teacher better". Other students' comments pointed to the teachers' use of resources found on computers to support learning activities in the class space. Two students undertaking PBL activities in the space noted that these classes were more successful than classes in more traditional spaces because of the ability to do research in class on computers to solve the problem presented by the facilitator.

However, a couple of students found the space "more difficult". One student wrote "I stuck to the same group of people ... situated on my pod. I didn't really interact with other students", while one student stated "I felt more distant from the students and didn't establish the same relationships" [as in other classes]. 
It should also be noted that that more than half of the student survey comments to questions one to four relevant to this element of the PST framework reported "no difference".

\section{Space (Master pod, pod desks, ottoman furniture and whiteboards)}

Most comments about the lectern in the Master pod were from the teachers. Half of these comments suggested that it was not required, or that it should be moved to the edge of a desk, or the edge of the room. The other half of the comments noted the barrier created by the lectern between the teacher and the students.

A very large number of participants responded positively to the pod-shaped desks and their contribution to effective group work. Half of the teachers commented on the organic group memberships that arose from the layout of the Pod space. The tightness and reliance on these micro-communities stimulated students to consider their membership preferences, more so than in a regular classroom. Half of the negative comments with respect to the physicality of the pods were related to the obtrusiveness of the computer monitors. Teachers acknowledged it was difficult to see students, and students reported the distraction between them and the teacher, or the presentation space at the front of the room. It was suggested by many that the monitors could be recessed in some way or stored flat in the desks. The other half of the negative comments in this category related to the distance between the five pods and these comments were mainly from the students who claimed little interaction between the pods due to the physical distance. This feeling was heightened with subjects with small class sizes in the Pod Room, where the distance between students and the teacher was seen as "too far".

A very large number of participants responded positively to the ottoman furniture and the informal/breakout learning space closer to the front of the Pod Room, in the sense that it created an inclusive forum for sharing ideas in full class discussion. It also had the effect of creating a sense of closer relationships between students stemming from the informal tone of the space overall. A single teacher suggested that the "huddle" in the ottoman area was much more productive than trying to share ideas on the class wiki. On the negative side, a couple of students commented on the difficulty in using computers or writing materials while in the ottoman space. A single teacher suggested that the space could be much larger.

While it was recognised amongst the teachers in the study that whiteboards are always useful, most teachers commented on the difficulty of transitioning between the "front" of the Pod Room and the whiteboards which were located on the side walls of the space. Even seeing the whiteboards from regular locations around the room (e.g. from the Master pod, the ottoman space and the far pods) was difficult, and this was confirmed during the class observations conducted during the study. The solution proposed by some teachers was for the whiteboards to be on wheels. It appears that the teachers were reluctant to provide the virtual whiteboard space afforded by the touch panel and its associated software at the Master pod. As noted in Table 1, the original intent of the whiteboards was to aid student groups for problem solving exercises.

A very large number of participants responded positively to the general feeling created by the room. Descriptors such as "ambience", "happy", "ultra-modern", "comfortable", "relaxed" and "informal" were used by respondents. Many of these comments were expanded to explain benefits to the learning process such as less fear 
and more ownership of the learning environment and the overall positive learning process afforded by the space. Interestingly, some students suggested that this space was not suited to their particular subjects.

\section{Technology (computers at individual pods, technology located within the Master pod and projection facilities)}

A large number of participants responded positively to the projection capabilities of the space, including the replication of projection at the front of the room across all pod monitors. The auxiliary laptop connection at each pod was also acknowledged. Teachers in the study spoke of perceived benefits of this projection feature in increased class discussion, a feeling of inclusion, a sharing of work, collaboration, enhanced competition amongst groups in class exercises and a reduction in passive behaviours by students. Some of the teachers reported the lack of a presentation remote control as restricting their movements in the Pod Room, and a few also reported a level of difficulty in operating the central control system with requests for further training and a "cheat sheet" located at the Master pod.

Participants also responded positively to the computer and Internet access for research and activities that engaged learners more than traditional worksheets. Teachers and students alike recognised the extended potential the technology afforded for PBL research, blogging, wiki creation, use of podcasts, presentation preparation and a discovery approach to learning that could be facilitated by the teacher with access to such a wide array of resources and tools. A single student reported increased confidence from the fast access to information provided by the technology, and another reported improved IT skills. The most frequent negative comment with respect to pod technology was that a single computer per pod is inefficient. Suggestions were made by students that multiple monitors at each pod would improve the workability of group computer use, but this comment was balanced by at least six comments from students related to the supportive team environment that arose when having only a single computer at each pod, which was the original intent of the design.

In summary, more than half of the negative comments relating to technology in general were in regards to reliability. One student stated that both students and teachers needed a "how to" lesson on using the technology because of difficulties in being able to correct any malfunctioning that occurred with technology in the room. A few general comments were made by teachers with regards to the overall availability of technologies, and the placement of this room somewhere between a classroom and a computer lab. There were also a few requests from teachers and students for improved audio capabilities at each pod, as the single earphone port was deemed impractical for multiple users.

\section{Conclusions and future research}

The Pod Room space in this study was an institutional response to the challenge of building a NGLS designed to foster collaborative and small group learning and facilitate the use of new technologies across the disciplines. The data arising from this pilot demonstrated the learning benefits achievable by the use of a space like the Pod Room. It is clear from the survey responses, particularly those of the teachers that the "Next Generation" orientation of the Pod Room contributed to enhanced learning 
experiences and opportunities for students. Through observation of and interviews with teachers, a variety of learning "blends" were being used that involved both activity, media and resource blends (Littlejohn and Pegler 2007), which provided some insights into the nature of blended learning made possible by this space, but also prompting ideas for future more focused research into the teachers' approaches to blended learning within this space. It is also important to highlight that the academic staff in this study were "learning by doing" in determining the most appropriate teaching approaches to use in this space. As reported in the literature review, teachers working in new learning spaces like the Pod Room require initial and ongoing support in relation to pedagogy and the appropriate use of technologies to enhance the student learning experience. There was no strong evidence gathered in this study as to how consistent teachers were in briefing students about their use of the space in particular subjects and any ongoing adjustments they may have had to make to the arrangements for group work in the space.

Given that this was a pilot study, there were a number of limitations that must be borne in mind while considering the findings presented in this article. An important consideration is the need for a greater depth of measuring user response to the Pod Room. For example, the use of video footage and student focus groups may reveal details of use and potential improvement of the space. More observations of individual teacher's use of the space would be needed to draw definitive distinctions between the differences in disciplinary use of the room and to tease out the relationship between a teacher's approach to teaching and the impact of that approach on the design of learning for the space. However, the larger question is whether learning was significantly improved as a direct result of the space. This would be a large undertaking requiring the qualitative and quantitative comparison of learning outcomes of students in the Pod Room as opposed to a standard classroom. Additionally, this study has not considered the effects of having some activities (particularly group and PBL) in the Pod Room while others are in more conventional settings.

The findings from the study also pointed to the need for changes to some areas related to technology and physical space in the design of future learning spaces at the university. Aspects of technology in the Pod Room which hindered what Long and Ehrmann (2005) called the "capabilities" of new learning spaces such as monitors obstructing views of the front of the room clearly need to be addressed when next an NGLS space is created. Compiling these points in the form presented in this article effectively adds to the design input process. In fact, many of the negative points raised by both teachers and students were technical and maintenance issues that have been rectified since this study was conducted. Most recently, the university has completed a technology review of the Pod Room, as much of the equipment was due for renewal. In consultation with the second author and users of the room, it was decided to address the issue of technical stability and robustness. As a result, some of the switching capabilities (such as from desk to desk) have been removed. However, software solutions that can more efficiently affect image switching are currently being investigated.

This study yielded a number of areas spanning all three dimensions of the PST framework discussed earlier in this paper that warrant further investigation - areas of learner interactivity, learner engagement, teacher and student use of specific technologies within the space, the impact of furniture provided in the space on learning design and discipline-specific approaches to use of this space. Also evident in 


\section{G. Wilson and M. Randall}

this study was a need for exploration of the nature and type of professional learning opportunities for academic staff working in new learning spaces, as well as an optimum way of delivering such support. Suggestions have been made in the literature that prototype spaces opened up to staff prior to timetabling of teaching in a new learning space is way in which staff understanding of the space and its capabilities can then inform the design of the subject and specifically the nature and type of learning activities that are possible within the space. Furthermore, this study has identified areas of enhancement and change that could be presented in a solid business case to university management.

\section{Acknowledgements}

The authors acknowledge the financial support provided by the Bond University Vice Chancellor's Research Grant Scheme used to fund research assistance for this work. The work of the two research assistants - Helga Noakes and Jason Daniels - employed in the literature review and data analysis stage of this project is also recognised. A previous version of this paper was published in the peer-reviewed proceedings of the 2010 conference of the Australasian Society of Computers in Learning in Tertiary Education (ASCILITE).

\section{References}

Andrews, T. \& Powell, D. (2009) 'Collaborative teaching and learning centres at The University of Queensland', in Learning spaces in higher education: Positive outcomes by design. Proceedings of the Next Generation Learning Spaces 2008 Colloquium, University of Queensland, Brisbane, eds D. Radcliffe, H. Wilson, D. Powell \& B. Tibbetts, University of Queensland and the Australian Learning and Teaching Council, Brisbane, pp. 38-39. Available at: http://www.uq.edu.au/nextgenerationlearningspace/proceedings

Brown, M. (2005) 'Learning spaces', in Educating the Net Generation, eds D. Oblinger \& J. Oblinger, Educause e-book, Chapter 12. Available at: http://net.educause.edu/ir/library/ pdf/pub71011.pdf

Brown, M. (2009) 'Inversions', Educause, vol. 44, no. 2, pp. 65-70. Available at: http:// www.educause.edu/EDUCAUSE\%2BReview/ERVolume442009/EDUCAUSEReview MagazineVolume44/163794

Brown, M. \& Lippincott, J. (2003) 'Learning spaces: more than meets the eye', Educause Quarterly, vol. 26, no. 1, pp. 14-16. Available at: http://www.educause.edu/EDUCAUSE + Quarterly/EDUCAUSEQuarterlyMagazineVolum/LearningSpacesMorethanMeetsthe/157 222

Dugdale, S. (2009) 'Space strategies for the new learning landscape', Educause, vol. 44, no. 2, pp. 51-62. Available at: http://www.educause.edu/EDUCAUSE\%2BReview/ERVolume 442009/EDUCAUSEReviewMagazineVolume44/163794

Francis, R. \& Raftery, J. (2005) 'Blended learning landscapes', Brookes eJournal of Learning and Teaching, vol. 1, no. 3, pp. 1-5. Available at http://bejlt.brookes.ac.uk/voll/volume 1issue3/perspective/francis_raftery.html

Hunley, S. \& Schaller, M. (2009) 'Assessment. The key to creating spaces that promote learning', Educause, vol. 44, no. 2, pp. 26-34. Available at: http://www.educause. edu/EDUCAUSE\%2BReview/ERVolume442009/EDUCAUSEReviewMagazineVolume44/ 163794

Huon, G. \& Sharpe H. (2009) 'Centre for Teaching and Learning Seminar Room', in Learning spaces in higher education: Positive outcomes by design. Proceedings of the Next Generation Learning Spaces 2008 Colloquium, University of Queensland, Brisbane, eds D. Radcliffe, H. Wilson, D. Powell \& B. Tibbetts, University of Queensland and The Australian Learning and Teaching Council, Brisbane, pp. 73-76. Available at: http://www.uq.edu.au/ nextgenerationlearningspace/proceedings

Jamieson, P., Dane, J. \& Lippman, P. (2005) 'Moving beyond the classroom: Accommodating the changing pedagogy of higher education', Refereed Forum Proceedings of the Australian Association for Institutional Research, pp. 17-23. Available at: http://www.aair.org.au/app/ webroot/media/pdf/AAIR\%20Fora/Forum2005/Jamieson.pdf 
Johnson, C. \& Lomas, C. (2005) 'Design of the learning space. Learning and design principles', Educause Review, vol. 40, no. 4, pp. 16-28. Available at: http://www.educause. edu/EDUCAUSE + Review/EDUCAUSEReviewMagazineVolume40/DesignoftheLearning SpaceLearni/157984

Joint Information Systems Committee. (2006) Designing spaces for effective learning. A guide to 21 st century learning space design, Joint Information Systems Committee, Bristol, UK. Available at: http://www.jisc.ac.uk/media/documents/publications/learningspaces.pdf

Lee, N. \& Tan, S. (2011) A comprehensive learning space evaluation model. Final report, The Australian Learning and Teaching Council, Sydney. Available at: http://www.altc.edu.au/ resource-learning-space-evaluation-swinburne-2011

Littlejohn, A. \& Pegler, C. (2007) Preparing for blended e-learning, Routledge, London.

Long, P. \& Ehrmann, S. (2005) 'Future of the learning space. Breaking out of the box', Educause Review, vol. 40, no. 4, pp. 42-58. Available at: http://www.educause.edu/ EDUCAUSE + Review/EDUCAUSEReview MagazineVolume40/FutureoftheLearning SpaceBreaki/157992

Long, P. \& Holeton, R. (2009) 'Signposts of the revolution? What we talk about when we talk about learning spaces', Educause, vol. 44, no. 2, pp. 36-48. Available at: http:// www.educause.edu/EDUCAUSE\%2BReview/ERVolume442009/EDUCAUSEReview MagazineVolume44/163794

Oblinger, D. (2005) 'Leading the transition from classrooms to learning spaces', Educause Quarterly, vol. 1, pp. 7-12. Available at: http://net.educause.edu/ir/library/pdf/eqm0512.pdf

Radcliffe, D. (2009) 'A pedagogy-space-technology (PST) framework for designing and evaluating learning places', in Learning spaces in higher education: Positive outcomes by design. Proceedings of the Next Generation Learning Spaces 2008 Colloquium, University of Queensland, Brisbane, eds D Radcliffe, H. Wilson, D. Powell \& B Tibbetts, University of Queensland and the Australian Learning and Teaching Council, Brisbane, pp. 11-16. Available at: http://www.uq.edu.au/nextgenerationlearningspace/proceedings

Radcliffe, D., et al. (eds) (2009) Learning spaces in higher education: Positive outcomes by design. Proceedings of the Next Generation Learning Spaces 2008 Colloquium, University of Queensland, Brisbane. University of Queensland and the Australian Learning and Teaching Council, Brisbane, Available at: http://www.uq.edu.au/nextgenerationlearningspace/ proceedings

Reushle, S., et al. (2009) 'Tell us about it: establishment of a technology-enhanced learning laboratory', in Learning spaces in higher education: Positive outcomes by design. Proceedings of the Next Generation Learning Spaces 2008 Colloquium, University of Queensland, Brisbane, eds D. Radcliffe, H. Wilson, D. Powell \& B. Tibbetts, University of Queensland and the Australian Learning and Teaching Council, Brisbane, pp. 111-116. Available at: http://www.uq.edu.au/nextgenerationlearningspace/proceedings

Temple, P. (2008) 'Learning spaces in higher education: an under-researched topic', London Review of Education, vol. 6, no. 3, pp. 229-241.

Tom, J., Voss, K. \& Scheetz, C. (2008) 'The space is the message. First assessment of a learning studio', Educause Quarterly, vol. 2, pp. 42-52. Available at: http://www.educause. edu/EDUCAUSE + Quarterly/EDUCAUSEQuarterlyMagazineVolum/TheSpaceIsthe MessageFirstAsses/162874 